\title{
Estudo da Evolução do Conceito de "Átomo" Através de uma Actividade com os Pais no Computador (APC)
}

\author{
Emanuel Alexandre Coutinho de Freitas Reis
}

Desde cedo o homem se interrogou sobre como a matéria seria constituída. A expressão "átomo" surgiu na Grécia antiga e marcou profundamente a Ciência. Embora o termo tenha perdurado, o conceito associado à palavra foi sendo refinado ao longo do tempo. Hoje, a palavra "átomo" designa algo completamente diferente das entidades idealizadas pelos filósofos gregos.

O átomo é uma entidade complexa mas fundamental para o estudo da química. No entanto, uma compreensão profunda da sua estrutura exige elevada abstracção.

Por este motivo, é frequente os alunos sentirem dificuldades no estudo da estrutura atómica. A estratégia tradicionalmente usada pelo professor consiste em apresentar sequencialmente um conjunto de modelos de cariz histórico, procurando evidenciar as características que motivaram a sua adopção e/ou substituição.

Contudo, muitos alunos acabam por limitar-se a memorizar as características dos modelos, por vezes de forma apressada, podendo inclusive

Centro de Investigação em Química, Departamento de Química e Bioquímica, Faculdade de Ciências, Universidade do Porto, Rua do Campo Alegre, 687, P-4169007 Porto, Portugal

Escola Secundária António Sérgio, Av. Nuno Álvares, S/n 4400-233 Gaia, Portugal desprezar ou deturpar a sequência cronológica apresentada. Nestas condições, torna-se difícil assegurar que as aprendizagens realizadas são de facto significativas e que não constituem uma eventual origem de ideias confusas [1, 2]. Esta situação é especialmente grave tendo em conta o carácter basilar dos conceitos em causa que, se não forem correctamente interiorizados, condicionarão decisivamente as aprendizagens futuras.

Apresentamos neste artigo uma sequência de tarefas que julgamos poder ser uma boa estratégia para abordar a evolução dos modelos atómicos e que se enquadra no que Paiva [3] caracteriza como "Actividades com os Pais no Computador" (APC).

Numa APC, o aluno é convidado a realizar em casa, com o auxílio de familiares (pai, mãe ou outro), uma série de tarefas de cariz tendencialmente investigativo que envolvem o uso do computador.

São várias as virtudes que podem ser apontadas a uma APC:

- Promove o envolvimento activo do aluno e compromete-o com o seu processo de aprendizagem

- Envolve e responsabiliza o Encarregado de Educação nas aprendizagens do aluno
- Promove o desenvolvimento e a mobilização de saberes/competências de diversas áreas no aluno

- Incentiva o uso do computador como uma ferramenta de produção e não apenas como um meio de consulta

- Promove e desenvolve no aluno capacidades de trabalho colaborativo/ cooperativo.

A presente APC foi elaborada de acordo com as orientações curriculares oficiais da disciplina de físico química e pensada para ser aplicada a alunos do nono ano do ensino básico.

\section{Agradecimentos}

Gostaria de agradecer ao Prof. Dr. João Paiva e à Mestre Carla Morais as preciosas sugestões que apresentaram.

\section{REFERÊNCIAS}

[1] Atomic Theory, http://jcflowers1.iweb. bsu.edu/rlo/chematomictheory.htm [consultado em 5/01/2011]

[2] Chemistry Misconceptions, http:// resources.educ.queensu.ca/science/ main/concept/chem/c07/C07CDTL1. htm [consultado em 6/01/2011]

[3] Paiva, João - Boletim da Sociedade Portuguesa de Química, 2010, 118, 57-63

\section{Vá a www.spq.pt}

Torne-se Sócio da Sociedade Portuguesa de Química e beneficie de:

- Pertencer a uma comunidade científica dinâmica;

- Receber o boletim "QUÍMICA";

- Descontos nos Encontros promovidos pela SPQ:

- Descontos nas publicações da SPQ;

- Protocolos assinados entre a SPQ e outras entidades;

- Participar na promoção da Química;

- Apoiar uma Sociedade Científica. 


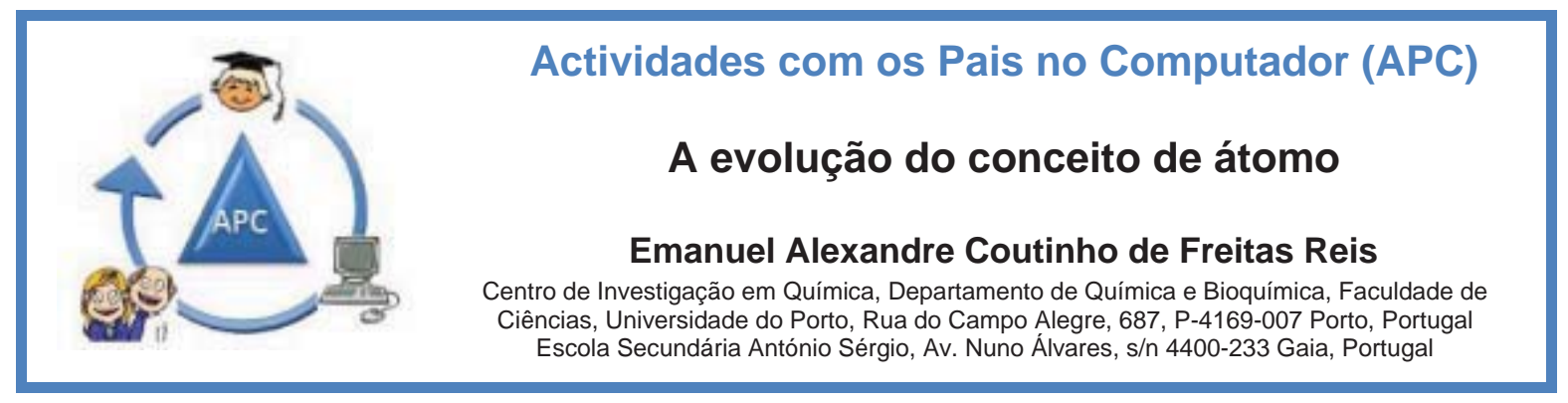

\section{A - Caros alunos e pais/ familiares:}

Nesta actividade, propomos que em conjunto explorem a forma como evoluiu o conceito de átomo ao longo dos tempos e percebam o impacto que essa evolução teve e continua a ter na Humanidade! Conhecer um pouco mais a História da Ciência ajudará a perceber como o conhecimento científico se constrói e progride. É muito importante que sigam todas as indicações que vos forem sendo apresentadas. O trabalho deverá ser entregue ao professor com este enunciado, podendo ser elaborado em formato digital, sob a forma de um ficheiro de texto, ou numa folha de papel. Neste ultimo caso, o cronograma e as figuras deverão ser impressas e coladas na folha a entregar. A secção $\mathbf{C}$ é para ser realizada individualmente pelo(a) aluno(a). Nas secções D, E e F constam as tarefas que o(a) aluno(a) e os pais (ou familiares) realizarão em conjunto. Bom trabalho e obrigado pela colaboração!

\section{B - Contexto:}

"Os Homens primitivos facilmente distinguiam os materiais que usavam para a confecção de roupas, para manufactura de ferramentas, ou simplesmente para a sua alimentação, tendo desenvolvido uma linguagem própria para descrever estas realidades, como "peles", "pedra" ou "coelho". Contudo, esses povos ancestrais não possuíam o nosso conhecimento sobre a constituição dos materiais." Adaptado de: Anthony Carpi, Ph.D. "Matter: Atoms from Democritus to Dalton," Visionlearning Vol. CHE-1 (1), 2003. http://www.visionlearning.com/library/module_viewer.php?mid=49

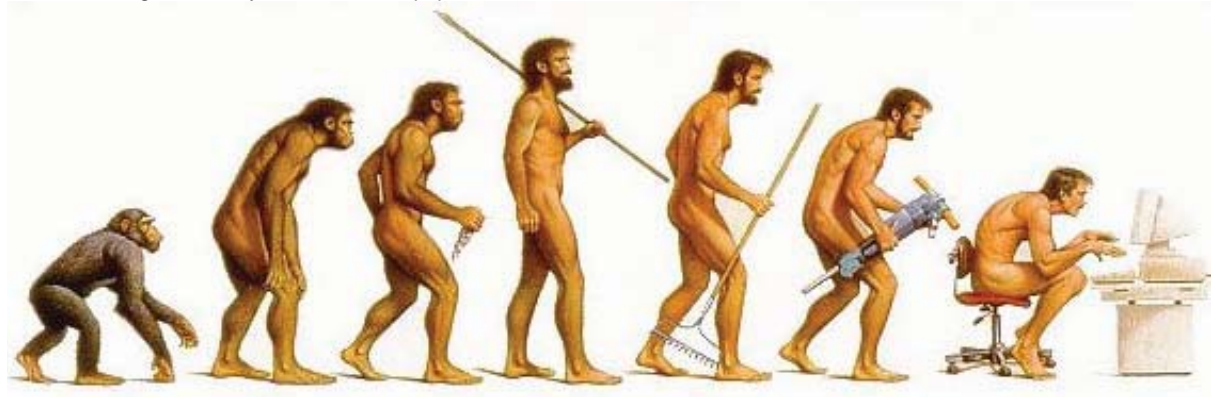

De facto, o mundo seria muito diferente se um conjunto de estudiosos ao longo dos anos não tivesse investigado a constituição da matéria. Não teria sido possível desenvolver novos materiais, as reacções químicas seriam fenómenos misteriosos e, por isso, provavelmente quase todas as comodidades e tecnologias que a Ciência proporcionou à Humanidade não existiriam. Ainda hoje, o estudo do átomo concentra a atenção dos cientistas, pois continua a ser uma fonte de novos conhecimentos, com impactos profundos em diversas áreas do saber.

\section{C - Área de trabalho individual:}
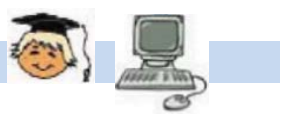

Até meados do século XIX, o átomo era considerado a menor partícula em que se poderia dividir a matéria. Mas tu já sabes que essa visão está desactualizada! Recordando o que já aprendeste no $8^{\circ}$ ano:

C1. Identifica os três tipos de partículas constituintes dos átomos, caracterizando-as quanto à massa, carga e localização no átomo.

C2. Distingue átomo, de molécula e de ião.

C3. Distingue substância elementar, substância composta e mistura de substâncias. 


\section{D - Área de trabalho colaborativo pais/alunos:}

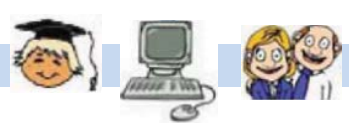

Dentro de cada uma das seis áreas a sombreado seguintes, encontra-se um pequeno texto que apresenta as ideias-chave que marcaram a forma como o Homem compreendia o átomo num dado momento que hoje marca a História da Ciência. Nestes textos, que não estão dispostos por ordem cronológica faltam algumas palavras.

Segundo o MODELO ATÓMICO DE os átomos seriam esferas de carga distribuída uniformemente, nas quais se encontravam dispersos os electrões,

com carga em número suficiente para que a carga eléctrica global do átomo

fosse

Este modelo, frequentemente conhecido como "modelo do bolo de passas", derrubou definitivamente a ideia da indivisibilidade do átomo, uma vez que considera a existência de no átomo.

\section{O MODELO ATÓMICO DE}

baseava-se nas seguintes hipóteses:

A matéria é constituída por corpúsculos muito pequenos, chamados átomos. Os átomos são partículas esféricas, maciças, indivisíveis, indestrutíveis, invisíveis a olho nu e electricamente neutras. Átomos do mesmo são idênticos.

Nas reacções químicas, os átomos não são nem , somente se modifica a sua distribuição. A combinação de iguais ou diferentes tipos de átomos origina os diferentes

\section{O MODELO ATÓMICO DE}

surgiu como consequência de uma experiência que provou que o átomo não era uma esfera maciça. De acordo com este modelo, o átomo era constituído por um núcleo que continha cargas eléctricas positivas - os - , e que os electrões giravam em torno deste núcleo, descrevendo órbitas elípticas (modelo planetário). Admitia ainda que, na região do núcleo, estava concentrada a quase totalidade da do átomo. Foi o primeiro modelo a prever a existência do núcleo e previu, também, a existência de um outro tipo de partículas sem carga - que só foram detectados experimentalmente, mais tarde, pelo físico

As TEORIAS são um conjunto de teorias surgidas na antiga, principalmente devido a Leucipo e que estabeleciam a ideia de que a matéria é constituída por pequeníssimos corpúsculos, a que se deu o nome de átomos (palavra que significa ).

Segundo o MODELO ATÓMICO DA não é correcto afirmar que o electrão percorre uma órbita.

Existe antes uma nuvem electrónica, resultante do movimento muito rápido dos electrões, constituída por que indicam as zonas do espaço em torno do núcleo, preferencialmente ocupadas pelos electrões dos diferentes níveis de energia.

Apenas se pode fazer referência à probabilidade de encontrar os electrões num determinado instante: a zona de maior probabilidade de encontrar os electrões situa-se junto ao , mas não nele próprio. A densidade electrónica é maior nas zonas interiores da nuvem; para regiões mais afastadas, a probabilidade de encontrar os electrões diminui, tornando-se a nuvem electrónica menos densa.

No entanto, átomos de diferentes têm tamanhos diferentes. O tamanho dos átomos relaciona-se com o afastamento dos em torno do seu núcleo. Ou seja, relaciona-se com o tamanho da sua nuvem electrónica.

De acordo com o MODELO ATÓMICO DE torno do núcleo, em órbitas circulares bem definidas.

A cada órbita corresponde um de energia.

Um electrão pode passar de uma órbita para a outra, por os electrões movem-se em de energia. Admitia que se o electrão recebesse energia poderia transitar para uma órbita de maior estado à qual corresponderia maior energia. O átomo ficaria, assim, num Esse estado seria instável, pois o electrão teria tendência a regressar ao estado de energia - o estado fundamental. 
D.1 Procura descobrir as várias palavras em falta em cada um dos textos anteriores com a ajuda do teu familiar. Para tal, recorre a algumas fontes de informação que consideres adequadas tais como: sítios da internet, livros, etc.

Nota: Caso pretendas entregar o trabalho em papel, deverás fotocopiar e recortar cada uma das áreas a sombreado para mais tarde colá-las na folha de trabalho. Se pretendes entregar em formato digital, poderás recorrer à funcionalidade "copiar/colar"/"copy/paste" para copiar os textos para o processador de texto.

D.2 Ainda com a ajuda do teu familiar e de outras fontes de informação, analisa cada um dos textos e estabelece a ordem cronológica correcta. Com a ajuda da Chave de Datas acede ao sitio http://www.teach-nology.com/web_tools/materials/timeline/ e elabora um cronograma ("timeline"), associando uma data ao nome do modelo/teoria a que cada um dos textos se refere.

\begin{tabular}{llllll|} 
Chave de Datas: sec VI a.c. & 1803 & 1897 & 1911 & 1913 & 1927 \\
\hline
\end{tabular}

Nota: Caso pretendas entregar o trabalho em papel, deverás imprimir a página com o cronograma que criaste, recortá-lo e depois colá-lo na folha de trabalho. Se pretendes entregar em formato digital, poderás recorrer à funcionalidade "ferramenta de recorte"/"snipping tool" do Windows Vista/7 (ou "printscreen" nas versões anteriores do Windows) para criar uma imagem do teu cronograma que depois poderás colar no teu processador de texto.

D.3 Procura na internet uma imagem que consideres ser uma ilustração adequada de cada um dos modelos atómicos do teu cronograma.

Nota: Caso pretendas entregar o trabalho em papel, deverás imprimir a imagem que escolheste, recortá-la e depois colá-la na folha de trabalho. Se pretendes entregar em formato digital, poderás inseri-la directamente no teu processador de texto.

\section{E - Para continuar:}

E1. Apesar desta investigação, poderão ter ficado algumas dúvidas ainda no ar. Deverão ser registadas todas as questões que subsistam para depois o aluno tentar esclarecer na escola com o auxílio do professor e dos colegas de turma.

E2. Hoje em dia os cientistas sabem que as partículas sub-atómicas consideradas nos modelos atómicos que estudaste não constituem o conjunto das partículas mais elementares da matéria. Investiga e procura listar quais as partículas que actualmente são consideradas mais elementares. Elabora um texto sistematizando os dados que recolheste.

E3. Investiga que actividades (pesquisas, experiências) têm sido realizadas no âmbito do estudo do átomo e das partículas que o constituem. Elabora uma apresentação contendo o resultado das tuas pesquisas.

\section{F - Avaliação dos intervenientes:}

Muito obrigado! Antes de mais, queremos agradecer pela colaboração e por todo o empenho colocado na realização desta actividade. Pedimos, por favor, que façam o preenchimento da tabela seguinte assinalando com uma $X$ a coluna que melhor corresponde à vossa opinião sobre o item em observação. Escala: 1- Muito Mau; 2- Mau; 3- Razoável; 4- Bom; 5- Muito Bom.

\begin{tabular}{|c|c|c|c|c|c|c|}
\hline & & 1 & 2 & 3 & 4 & 5 \\
\hline \multirow{2}{*}{1 - $O$ que achei do desafio inerente à actividade } & Pais & & & & & \\
\hline & Aluno & & & & & \\
\hline \multirow{2}{*}{$\begin{array}{l}2 \text { - Como foi o meu desempenho nas questões técnicas, com o } \\
\text { computador? }\end{array}$} & Pais & & & & & \\
\hline & Aluno & & & & & \\
\hline \multirow{2}{*}{3 - Como foi o nosso nível de diálogo? } & Pais & & & & & \\
\hline & Aluno & & & & & \\
\hline \multirow{2}{*}{4 - Contributo para a melhoria dos conhecimentos científicos? } & Pais & & & & & \\
\hline & Aluno & & & & & \\
\hline \multirow{2}{*}{5 - Contributos para melhorar a vida, pessoal e em sociedade? } & Pais & & & & & \\
\hline & Aluno & & & & & \\
\hline \multirow{2}{*}{$\begin{array}{l}\text { 6- Contributos desta actividade para relacionar harmoniosamente } \\
\text { o computador, o estudo e o diálogo familiar? }\end{array}$} & Pais & & & & & \\
\hline & Aluno & & & & & \\
\hline \multirow{2}{*}{$\begin{array}{l}7 \text { - Como estava a proposta inerente à actividade em termos de } \\
\text { clareza, motivação e recursos fornecidos? }\end{array}$} & Pais & & & & & \\
\hline & Aluno & & & & & \\
\hline \multirow{2}{*}{8 - Na globalidade como avalio esta actividade? } & Pais & & & & & \\
\hline & Aluno & & & & & \\
\hline
\end{tabular}

Outras observações:

Grato,

O Professor 